Las Torres de Lucca. Revista internacional de filosofía política

ISSN-e: 2255-3827

\title{
Participación política y libertad del pueblo: apuntes para pensar el republicanismo arendtiano en las disputas del presente ${ }^{1}$
}

\author{
Paula L. Hunziker²; Julia Smola ${ }^{3}$
}

Recibido: 5-5-2020 / Aceptado: 30-8-2021/ Publicado: 30-01-2022

Resumen. Este escrito surge de nuestras investigaciones sobre la caracterización y las fuentes del republicanismo arendtiano, y pretende intervenir en la temática propuesta para este número acerca de la participación política en nuestras democracias contemporáneas. En este panorama quisiéramos ubicar nuestras reflexiones con la expectativa de reintroducir, a través del pensamiento de Hannah Arendt, ciertos aspectos que consideramos centrales para pensar la república y que han sido dejados de lado en el debate público sobre los regímenes políticos contemporáneos. Estos son el lugar del pueblo en la república, su función y su dinámica política en la vida de las instituciones y en la expresión de la libertad en el orden político contemporáneo. En este trabajo, sostendremos que las reflexiones de Arendt sobre la república están íntimamente ligadas a la figura, o deberíamos decir mejor, a las múltiples figuras del pueblo y al rol que ellas juegan en la institución política de la libertad.

Palabras Clave: Arendt; libertad política; participación política; pueblo; republicanismo.

\section{[en] Political Participation and Freedom of the People: Notes on Arendtian Republicanism for Today's Disputes}

Abstract. This paper derives from our research on the characterization and sources of Arendtian republicanism, and aims to intervene in the theme proposed for this issue about political participation in our contemporary democracies. In this context, we would like to place our ideas with the expectation of reintroducing, through Hannah Arendt's thought, certain aspects that we consider to be central in order to think about the republic which have been neglected in the public debate on contemporary political systems. Such are the place of the people in the republic, their function and their political dynamics in the life of institutions and in the expression of freedom in the contemporary political order. In this paper, we will argue that Arendt's reflections on the republic are intimately linked to the figure, or should we say, to the multiple figures of the people and to the role they play in the political institution of freedom.

Keywords: Arendt; political freedom; political participation; people; republicanism.

Cómo citar: Hunziker, P. L.; (2022). Smola, J. Participación política y libertad del pueblo: apuntes para pensar el republicanismo arendtiano en las disputas del presente. Revista internacional de filosofía política, 11(1), pp. 79-88. https://dx.doi.org/10.5209/ltdl.77047

Este trabajo surge de nuestras investigaciones sobre la caracterización y las fuentes del republicanismo arendtiano y pretende intervenir en la temática propuesta para este número acerca de la participación política en nuestras democracias contemporáneas. En efecto, como revelan los últimos acontecimientos en el Cono Sur, puede percibirse un cierto agotamiento de las categorías con las que pensamos nuestros regímenes políticos y una enorme debilidad de los propios sistemas democráticos para hacer frente a fuerzas que lo erosionan. Nos referimos a acontecimientos de características muy diversas, como las protestas en Chile de fines del 2019, y el golpe de Estado en Bolivia también a fines de 2019; remontándonos unos años más atrás, al proceso de destitución de Dilma Rousseff, al Juicio político a Fernando Lugo y a los procesamientos judiciales a varios líderes políticos

\footnotetext{
Nuestras investigaciones se enmarcan en el proyecto colectivo "La tradición filosófica y política desde la perspectiva de Hannah Arendt. Lecturas modernas y apropiaciones contemporáneas" (PICT 2014-1422).

Expusimos una versión mucho más breve y menos desarrollada de este texto en el X Encuentro Interdisciplinario de Ciencias Sociales y Humanas: "Las urgencias del presente: Desafíos actuales de las ciencias sociales y humanas," llevado a cabo el 27,28 y 29 de noviembre de 2019 y organizado por el CIFFyH y el Instituto de Humanidades (IDH), CONICET, que luego fue publicado en actas.

2 Centro de Investigaciones Filosóficas de la Facultad de Filosofía y Humanidades, Universidad Nacional de Córdoba, Argentina.

Correo electrónico: paulahunziker@gmail.com.

ORCID: https://orcid.org/0000-0002-3963-2844

3 Instituto del Desarrollo Humano, Universidad Nacional de General Sarmiento, Argentina.

Correo electrónico: jsmola@campus.ungs.edu.ar

ORCID: https://orcid.org/0000-0002-7201-2700
}

Las Torres de Lucca. 11 (1), 2022: 79-88 
que los excluyen de la participación como candidatos en procesos electorales. La democracia, en su versión más formal, se ha vuelto un corset muy estrecho para pensar los proyectos políticos progresistas en la región. Además, el propio sistema democrático aparece como un límite muy lábil para hacer frente a las poderosas derechas económicas, políticas y sociales que expresan un gran desapego, no solo por el ejercicio de la soberanía popular, sino por el respeto a las mínimas garantías legales y a las instituciones más básicas de la república.

En este panorama quisiéramos ubicar nuestras reflexiones, con la expectativa de reintroducir, a través del pensamiento de Hannah Arendt, ciertos aspectos que consideramos centrales para pensar la república y que han sido dejados de lado en el debate público sobre los regímenes políticos contemporáneos. Por ello, no nos ocuparemos de enfoques que no ponen el centro de interés en una discusión y apropiación del concepto de república, como la línea de intérpretes de Arendt cuya-reflexiones surge de su emparentamiento y polémica con las formulaciones de Jacques Rancière. Estas posiciones que han sido retomadas en algunas lecturas latinoamericanas de la autora acentúan la dimensión performativa, asambleísta, no-estatalista, disruptiva de la acción (Quintana, 2015; Carmona Hurtado, 2014), lo que las aleja del debate en el que queremos inscribir nuestro texto. En este trabajo, nos dedicaremos, entonces, a discutir con las posiciones que, en el ámbito de las teorías y las prácticas, asumen el nombre del republicanismo como forma de revitalizar la democracia en dos sentidos: el lugar de la participación política del pueblo en la república, su función y su dinámica política en la vida de las instituciones; y en la expresión de la libertad en el orden político contemporáneo. Sostendremos que las reflexiones de Arendt sobre la república están íntimamente ligadas a la figura, o deberíamos decir mejor, a las múltiples figuras del pueblo y al rol que ellas juegan en la institución política de la libertad.

La hipótesis que intentaremos argumentar en lo que sigue es que el tipo de participación política que propone Arendt resulta en una forma de libertad que se distingue tanto de las versiones liberales como de las versiones de la libertad neo-republicanas.

Desarrollaremos el presente escrito en tres pasos: en primer lugar, intentaremos establecer cuáles son los parámetros centrales de la concepción de libertad política para nuestra autora. Esta operación permitirá alejarnos de interpretaciones que la emparentan con posiciones francamente liberales, así como de aquellas que la acercan a las ideas neorrepublicanas de libertad negativa como no dominación (Pettit, 1999). Por el contrario, sostendremos la originalidad y fertilidad de idea de libertad arendtiana -como participación cívicapara la contemporaneidad; en segundo lugar, reflexionaremos sobre la concepción del pueblo en su obra, a fin de establecer su lugar dentro de la constitución de la república, distanciándonos de lecturas preocupadas por la subjetivación política y remarcando la importancia que para la autora adquiere el carácter colectivo del sujeto político que actúa; en última instancia, y como corolario de estas discusiones, intentaremos resaltar lo que, a nuestro entender, su pensamiento sugiere para superar el debate dicotómico populismo-liberalismo sobre nuestras democracias contemporáneas.

\section{La libertad republicana como participación cívica}

Debemos al ya clásico libro de Philip Pettit, Republicanismo. Una teoría sobre la libertad y el gobierno (1999), una singular lectura de Hannah Arendt. Para el autor, según el cual la libertad republicana debe entenderse a partir de la idea de no dominación, en el sentido de la no interferencia arbitraria, la filosofía arendtiana queda separada del panteón republicano por la fuerte presencia en su obra de componentes de un tipo de libertad positiva que hace cuestionable su filiación a esa tradición. Efectivamente, para Pettit, Arendt es ejemplo de una línea populista que identifica libertad y participación democrática en el gobierno de los asuntos comunes. Si bien Pettit reconoce que "los pensadores republicanos consideraron en general que la participación o la representación democráticas eran una salvaguardia de la libertad" (1999, p. 50), este no sería el núcleo definitorio de tal concepto. En este horizonte, Arendt no estaría sola, sino que sería ubicaba junto a todos aquellos pensadores modernos y contemporáneos cuyo énfasis en la democracia los lleva a separarse de aquella libertad republicana y "acercarse a una posición populista, de acuerdo con la cual la libertad consiste, ni más ni menos, que en el autodominio democrático" (Pettit, 1999, p. 50). Tal movimiento conduce, por un lado, a una recuperación de la democracia griega o alguna de sus figuraciones, y por otro, a un giro populista que cobra forma definitiva cuando

el ideal del autodominio democrático se convirtió en la principal alternativa $-\mathrm{o}$ al menos, en la principal alternativa entre las distintas nociones de libertad- al ideal negativo de la no-interferencia. Pensar que la tradición republicana es populista, como -huelga decirlo- han hecho tantos, monta tanto como afirmar la misma dicotomía que ha tornado invisible al ideal republicano. (Pettit, 1999, pp. 50-51).

En este primer apartado, nos proponemos pensar cómo la obra de Arendt aporta elementos para no oponer -tal como lo hace Pettit y junto con él todo un elenco de autores- lo que se denomina libertad democrática a la libertad republicana, sino para pensarlas en común. El modo de esta comunidad es iluminado por Arendt gracias a un enfoque histórico hermenéutico que permite trazar de otra manera las fronteras conceptuales y 
las disputas del presente. Esto es, su enfoque muestra que existen motivos histórico-hermenéuticos de peso para reflexionar sobre esa comunidad, brinda buenas razones para pensar en la posibilidad de su articulación conceptual, y, en conjunto, es una voz singular que puede aportar elementos para plantear de otro modo los problemas políticos y conceptuales de las democracias contemporáneas.

Por una parte, la prioridad que la autora da al espacio político clásico griego no conduce a una glorificación sin más de la libertad democrática como la participación en el gobierno de los asuntos comunes, sino a recuperar la participación del demos en el centro de gravedad de una herencia que hace sentido en la experiencia política romana, así como en su idea de libertad republicana. Se trata de ir con Atenas, más allá de Atenas, no de contraponer un modelo a otro. Arendt nos ayuda a pensar la complejidad hermenéutica de esta relación, esto es, el modo en que la libertad republicana surge de una lectura romana del mundo clásico. Si bien es cierto que el propio liberalismo, como muestra Pettit siguiendo a autores como Skinner, surge de una confrontación con el republicanismo, y esta hipótesis enriquece la autocomprensión liberal de su historia, es importante pensar con Arendt que el propio republicanismo tiene una larga deriva previa que comienza con la reelaboración romana de la libertad democrática clásica: libertad que no solo no es contradicha por los principios de organización de la Roma republicana, sino que busca fortalecerlos y ampliarlos.

Por otra parte, la importancia que en el seno de la reconstrucción arendtiana de un republicanismo moderno adquiere Maquiavelo como autor republicano y lector de la experiencia romana permite poner en duda que, incluso en el seno de la modernidad, sea posible sostener que el discurso republicano involucre sin más una subordinación del sentido de la libertad como participación del demos en los asuntos comunes al fin de la libertad como no interferencia arbitraria en la vida de cada uno.

Por ambos niveles de la reconstrucción histórico-hermenéutica de Arendt, diferenciamos nuestra lectura de la recuperación de una "Arendt republicana," que Andrés Rosler lleva adelante en Razones públicas. Seis conceptos básicos sobre la república (2016). Hemos desarrollado parte de nuestra argumentación respecto de este libro en (Hunziker, 2019). Para nuestros fines aquí, cabe decir que su lectura es generosa y amplia, reconociendo en varios pasajes el aporte de Arendt al redescubrimiento contemporáneo del republicanismo. No obstante, acepta el diagnóstico de Pettit, que consideramos cuestionable, en dos sentidos. Por un lado, destaca la lectura arendtiana del mundo romano, sin tener en cuenta la centralidad que para esta autora tiene el modo en que el mundo romano elabora la herencia griega (sin dejar de poner como clave de bóveda la experiencia de la libertad como participación en los asuntos comunes). Por otro lado, esta operación forma parte de lo que parece ser una hipótesis más amplia de Rosler: que los lectores republicanos modernos descubren en Roma un concepto de libertad republicana que subordina la libertad como participación en los asuntos comunes a la libertad como no-dominación, esto es, como "no interferencia arbitraria" en la vida de cada uno (Cf. Rosler, 2016, pp. 56-66). En el apartado "La concepción republicana" de su primer capítulo sobre "La libertad," Rosler explica la especificidad de una concepción republicana de la libertad definida en los términos de "no interferencia arbitraria," que "navega un curso medio" entre la concepción liberal-negativa de la mera no interferencia y la concepción positiva de autogobierno en tanto posibilidad de acción sin impedimentos externos. Esta definición que Rosler repone forma parte, en realidad, de un debate que lleva ríos de tinta y puede encontrarse en muchos otros textos de autores neo-republicanos (Skinner, 2005; Pettit, 1999; Pocock 2002). Nuestra intención no es identificar nuevamente la libertad republicana -en su versión arendtiana- con la señalada versión positiva de la libertad (en particular como se la ha caracterizado desde Isaiah Berlin en adelante), sino mostrar los límites conceptuales y políticos de subordinar la idea de participación del demos al fin de la no-interferencia-arbitraria. En lo que sigue utilizamos la reflexión de Arendt -en especial la que encontramos en La Condición Humana (1993)- para mostrar la posibilidad de entender la libertad republicana de manera diferente. Esta diferencia no es solo una diferencia conceptual, sino una que aborda la importancia de la recuperación romana del mundo clásico griego como un acontecimiento central que debe ser tenido en cuenta para analizar la propia experiencia romana y su "filosofía política," su elenco de conceptos.

Para comenzar, proponemos dejar en suspenso la etiqueta de neoaristotelismo para todos los autores que vuelven al mundo griego en clave republicana. En el caso de Arendt, fue Jürgen Habermas el primero que contribuyó a una lectura filosófica de su obra, al situar a La condición humana (1993) como uno de los textos fundacionales del aristotelismo contemporáneo (Forti, 2001; Habermas, 2000). Más allá de la importancia que esta recuperación tuvo para el campo de la filosofía y de la teoría política, numerosos textos en los últimos veinte años se han encargado de matizar y de contextualizar la lectura arendtiana de Aristóteles, acentuando su punto de partida posfundacional de "crítica de la filosofía política" (Forti, 2001), la importancia de una sutil confrontación con Heidegger (Taminiaux, 1998; Forti, 2001; Benhabib, 2000), la discusión con el marxismo, etc. En esa línea, pero centrándonos en especial en su lectura de la experiencia y del pensamiento político en su historicidad, en este trabajo abordamos la lectura de Aristóteles de la autora de La condición humana, como una defensa republicana de la libertad de participación del pueblo como centro de la dinámica política.

Para delimitar nuestro análisis es preciso articular esa libertad de participación con la fenomenología de la praxis política como espacio de revelación del mundo político y de los actores en tanto agentes. Esto es, que haga depender el concepto de libertad de una teoría de la acción política y de la agencia. En la base de la dinámica de la polis griega, Arendt cree descubrir la experiencia pre-polis del mundo público como espacio 
de aparición y revelación de los hombres en tanto hombres -hay que retener el plural- cuya existencia y permanencia se obtiene por la articulación entre praxis y discurso, y por el carácter plural del logos que esta última supone.

Lejos de idealizar el mundo clásico, en La condición humana, la autora manifiesta los límites de este modelo, con lentes casi romanas. Lo interesante para nuestra discusión es que ninguno de esos límites tiene que ver con los "desmadres" de la participación del demos, sino con la posibilidad de conservarla, y ampliarla. Ello exige, según la autora, por una parte, pensar en una mayor complejidad institucional -una institucionalidad de la praxis política republicanamente comprendida-, y por otra parte, pensar en una mayor complejidad de la subjetivación política, de la agencia -que incluye la libertad respecto de la política con el socrático descubrimiento de que no estoy con otros, sino también conmigo mismo.

Este conjunto de problemas serán retomados por el mundo romano, pero sin abandonar esa idea de libertad como participación, sin la cual no se entendería el descubrimiento romano de la importancia de la elaboración de las leyes, la centralidad de la promesa en la fundación y en la alianza entre los pueblos, todos estos modos de preservación y de ampliación de la libertad. Arendt valorará estos descubrimientos, pues suponen una salida política a las tensiones de la polis de Pericles, tensiones que ella misma señala en su libro más "griego". Efectivamente, en La condición humana establece una serie de juicios severos, en los que la ciudad es cuestionada en la medida en que no logra conservar, redefiniéndola, aquella experiencia pre-polis de la acción como política, como experiencia de libertad de los hombres, que tiene su expresión primera en el espacio de la prosa homérica. A riesgo de ser esquemáticas, señalamos tres aspectos de esta crítica.

En primer lugar, la autora indica que la estrecha vinculación entre acción y discurso no se conserva en el más hablador de los cuerpos políticos, que progresivamente convierte al discurso político en un medio de persuasión de los individuos - un instrumento de dominio- y no de explicitación de una relación personal, prácticamente mediada, con el mundo común, de respuesta a "lo que nos pasa" y de asumir una "responsabilidad", así como de revelación de ese mundo en tanto común.

En segundo lugar, Arendt insiste en las dificultades de la agonalidad griega, cuyo énfasis en la distinción hace palpable el ser distinto, pero corre el riesgo de socavar la visibilidad del principio de igualdad. Efectivamente, la autora señala que, dado el carácter individualista del concepto griego de acción se acentuó en exceso

la urgencia de la propia revelación a expensas de otros factores ... Como tal, pasó a ser el prototipo de la acción para la antigüedad griega e influyó, bajo la forma del llamado espíritu agonal, en el apasionado impulso de mostrar el propio yo midiéndose en pugna con otro (Arendt, 1993, p. 217).

Este aspecto se conecta con otro central para la consagrada interpretación de Margaret Canovan (2002a). La experiencia de la prosa homérica es la de uno que se aventura en una empresa y que es seguido por otros como un primus inter pares: uno que se destaca entre iguales, y en la medida en que son iguales. La acción colectiva no supone la igualdad de la homogeneidad, sino una igualdad de singulares que son diferentes.

Por último, encontramos los problemas de una excesiva confianza en la realidad de la praxis y el discurso (que para la interpretación de la autora debe pensarse en su esencial articulación con el poder como dynamis) para preservar su memoria póstuma: la gloria de los actores y el sentido de sus actos. Aquí aparece el concepto de poder como posibilidad de los hombres que actúan y hablan, y no como una propiedad del individuo, o sea, "una intercambiable, mensurable y confiable entidad como la fuerza" (Arendt, 1993, p. 223). Además, surge el problema de su perduración, que no es solo institucional, sino también de sentido y de herencia.

Es interesante que ese señalamiento sea dirigido a la Oración fúnebre (Tucídides, II, 41) y a la creencia orgullosamente defendida de que "el íntimo significado del acto actuado y la palabra pronunciada es independiente de la victoria y la derrota y debe permanecer intocado por cualquier resultado final" (Arendt, 1993, p. 233). En este caso, La condición humana abre la pregunta por la narración histórica como artefacto para la constitución misma del espacio político -algo que se explicitará en otros textos (Arendt, 1996a; Arendt, 1997, pp. 115-130)-. A ojos de la autora, si bien este aspecto supone una valorable y antigua fe en la política como tal, deja de lado, al menos como problema político, aspectos centrales ligados a la finitud de la propia praxis, y, en especial, no resuelve una inquietud que ya está presente en su texto sobre Sócrates de 1954: la pregunta por una dimensión pública no estrictamente política, ligada al testigo y habilitada por el pensamiento, por una parte, y la pregunta por la ley y la estabilidad brindada por la ley, por la otra.

En el horizonte problemático de una polis que no asume sus limitaciones, Arendt destaca el modelo romano como un conjunto de invenciones fundamentales, en especial vinculadas con la institucionalidad republicana, que llega hasta nuestros días. Como bien señala Andrés Rosler (2016), Hannah Arendt es una de las primeras en mostrar la importancia de la experiencia romana para pensar en algunos conceptos centrales de un redescubrimiento (gracias a ella) del republicanismo moderno: en Maquiavelo, Montesquieu, Tocqueville. Respecto de esa experiencia romana, Arendt destaca, sucesivamente, una interpretación política de la ley como constitutiva de la libertad de todos, como relación y no como límite; la articulación entre acción política, ley e institución republicana de la libertad; la positividad de la división para la conservación del poder; la 
importancia de la promesa y del juramento como centro de la legitimidad de las instituciones republicanas de la libertad; y la necesidad de la autoridad de la ley, no de los hombres.

No obstante, en esta operación de institucionalización, de domesticación de la salvaje Atenas -valga la ironía-Arendt señala dos cosas. De un lado, que para el mundo romano, la libertad está ligada a la participación de la plebe en los asuntos públicos y a la capacidad de Roma de generar alianzas. Ambas nociones articulan esa libertad positiva griega. Así, contra la tesis de Pettit, la institucionalidad republicana es un medio para la libertad como participación, y no a la inversa. Los hombres participan en la res pública, no porque no quieran ser dominados, sino porque son libres cuando actúan con otros, y en tanto actúan. Esta consideración se ve reflejada también en las fuentes republicanas que, como ya señalamos, toma Arendt, y en su particular lectura de Maquiavelo, quien se acerca a la experiencia romana -por retomar una expresión de la autora- despojado de las lentes filosóficas legadas por la tradición.

Sus propias experiencias en las luchas de su tiempo enseñaron a Maquiavelo un hondo desprecio por todas las tradiciones, cristiana y griega, tal como las presentaba, nutría y reinterpretaba la Iglesia ... La grandeza de su redescubrimiento reside en que no podía sólo restaurar o recurrir a una articulada tradición conceptual, sino en que él mismo tuvo que articular esas experiencias que los romanos no habían conceptualizado sino puesto en términos de una filosofía griega divulgada para esos fines. (Arendt, 1996b, pp. 149-150).

En este sentido, Maquiavelo nos presenta la historia romana, no como la narra Cicerón en De república -como la invención de los primeros reyes que despliegan a lo largo de la historia romana-, sino como el resultado de los tumultos entre los grandes y la plebe, y las leyes romanas como aquello que surgió de la participación política del pueblo (Maquiavelo, 1996, pp. 27-52). La de Maquiavelo resulta así una idea de libertad republicana como no-dominación que es muy distinta de la que recupera Pettit. ${ }^{4}$ Más cerca de la idea de Arendt, para el florentino, los hombres son libres, es decir, no son dominados, solo cuando y en la medida en que actúan con otros. Solo en la medida en que se enfrentan, a través de su acción y de la fundación de un régimen político, al deseo de dominación de los grandes.

El problema político no es el de racionalizar la participación, sino el de institucionalizar esa participación: cómo conservarla y ampliarla. Del otro lado, Arendt entiende -aunque no comparte- el gesto de mirar el problema político republicano como el de una racionalización -esto es, como una teoría que busca "civilizar" sus componentes democráticos más salvajes- dado que son los propios espectadores filósofos romanos, los que se ubican por detrás - dan un paso atrás- de sus invenciones como actores de la república romana. Sabida es, en este sentido, la interpretación arendtiana del final de La república ciceroniana como escrito crepuscular, que apuntala un lugar en la eternidad para soportar el necesario fracaso de las causas más nobles. Un placer retrospectivo y melancólico del fracaso -de Cicerón el filósofo- es lo que queda del amor por la patria del senador romano.

Una primera conclusión es que eso que en cierta lectura republicana del presente se denomina como el peligro de la libertad positiva o democrática, no hace sentido en la óptica de Arendt. Por el contrario, la autora considera que sin esa libertad, el concepto republicano de lo político no tiene sentido. No obstante, Arendt reconoce una serie de peligros, que no están en la libertad como tal (y que por eso haya que controlar), sino en su fragilidad en un horizonte amenazado, en especial, por una serie de fenómenos modernos que destituyen o ponen en crisis al sujeto de la libertad en tanto actor mundano, y que, defenderemos, puede ser abordado a partir de la categoría de pueblo.

\section{La concepción del pueblo en el republicanismo arendtiano}

Las ideas de Arendt sobre la república están, sin dudas, inspiradas en este republicanismo clásico (en el preciso sentido que desarrollamos en el apartado anterior) pero con preocupaciones modernas, como argumentó Canovan en Hannah Arendt: a reinterpretation of her political thought (2002a). Sin embargo, es tal vez un aspecto del cual Canovan no se ocupa particularmente en su libro sobre el republicanismo arendtiano -pero que es el objeto de otros textos (Canovan, 2002b) ${ }^{5}$ - lo que pueda ayudar a caracterizar de mejor forma su pensamiento $y$, a los fines de este artículo, lo que pueda contribuir a pensar las disputas del presente ofreciendo otras relaciones conceptuales. Esto es, el lugar del pueblo en su pensamiento político.

En efecto, Pettit no es el único en considerar el populismo de Arendt. Autores que se han dedicado largamente a la interpretación de su obra sostienen que el pueblo constituye una categoría central de su pensamiento político. Para Richard Bernstein, por ejemplo, existe una veta populista o radical en el pensamiento de Arendt

\footnotetext{
Ernesto Funes señala que, en su opinión, Pettit no destaca "suficientemente la relevancia histórica que para el concepto de no-dominación tiene la reflexión política de Nicolás Maquiavelo.” (Funes, 2004, p. 31 nota al pie $n^{\circ} 2$ ). Nosotras agregamos que dicho olvido tiene consecuencias sobre el desarrollo conceptual de la libertad republicana y de la acción, entre ellas la importancia que Maquiavelo otorga a la dinámica política que crean los tumultos entre los grandes y la plebe.

Más adelante, en su libro desarrolla ella misma una teoría sobre el pueblo (Canovan, 2005).
} 
en el sentido que el tipo de política que ella favorece e intenta defender es aquella donde la acción colectiva espontánea surge de un pueblo que crea sus propios espacios públicos, donde discurso y actos hacen su aparición (1996, p. 61). Esta línea de pensamiento, invita a pensar una versión menos elitista de su republicanismo. Así, también Canovan considera que Arendt plantea un populismo pero que el mismo resulta paradojal ya que mientras acepta la acción directa del pueblo, también teme y deplora casi todos los casos reales de movilización popular (2002b, p. 403). En este sentido, ambos autores recuerdan la distinción arendtiana en Los orígenes del totalitarismo (1998), que se ocupa de separar diferentes manifestaciones populares en la escena pública: el populacho, las masas y la tribu. Asimismo, la forma en que las multitudes hambrientas entran en la escena pública durante la revolución francesa se distingue del pueblo organizado en asambleas populares y consejos durante la Comuna francesa y durante la revolución americana. Estas formas de organización se repiten, dice Arendt, en "todas las revoluciones dignas de ese nombre" (1992, p. 257): los soviets rusos de 1905 y febrero de 1917, los räte alemanes de 1918 y 1919, los consejos de la revolución húngara en 1956. Todas, según Etienne Tassin (2012), revoluciones que fracasaron pero que también fueron manifestaciones de un pueblo en acción.

En este apartado, intentaremos rastrear la noción de pueblo en el pensamiento de Hannah Arendt haciendo una breve reconstrucción de los usos y los sentidos que asume en parte de su obra. Para realizar esta tarea comenzaremos por algunos textos que Arendt escribió en la década del cuarenta, en particular "La tradición oculta" que vio la luz apenas dos años de finalizada la guerra en 1947. Aun cuando la bibliografía que trabaja la cuestión del republicanismo arendtiano se centra en su libro sobre el totalitarismo, en algunos pasajes de $L a$ condición humana (1993) y en el análisis crítico de la fundación de los cuerpos políticos en la modernidad que desarrolla en Sobre la revolución (1992), creemos insoslayables los aportes hechos en sus escritos judíos. Al respecto, Richard Bernstein (1996) señala que muchos de los dilemas del pensamiento político de Arendt se presentan en sus escritos sobre la cuestión judía.

Martine Leibovici (2005) y Fina Birulés (2005) acuerdan con la hipótesis general del libro de Bernstein acerca de la centralidad que esta pregunta reviste para todo el pensamiento de la autora. De hecho, Leibovici recuerda que, en una carta a Jaspers del 29 de enero de 1946, Arendt sostuvo que no había "dejado jamás de orientarse política e históricamente a partir de la cuestión judía." (2005, p. 8). Más adelante, Leibovici aclara que:

eso no significa que haya querido abordar la política a partir de este único punto de vista, sino que los atolladeros y los desastres que los judíos tuvieron que enfrentar en el siglo XX fueron directamente reveladores de los atolladeros y los desastres de la política en la época del totalitarismo. (2005, p. 10).

A partir del momento en que Arendt expresó haberse sentido políticamente responsable por el ascenso del nazismo en Alemania, intentó desarrollar un pensamiento que tuviera en cuenta el rol del pueblo judío en aquella historia que cristalizó con los totalitarismos. A pesar de no haber recibido una educación religiosa ni sentir "amor por el pueblo judío" - como le reprochó Scholem-Arendt se sentía parte "más allá de toda discusión." Su judeidad -a diferencia del judaísmo, observa Leibovici- era "uno de los datos irreductibles de su vida" (carta a G. Scholem, 24 de Julio de 1963, en Leibovici, 2005, p. 9).

¿Pero qué sentido podía tener esta pertenencia al pueblo judío para alguien que fue educada de manera laica y que como ella misma indica, aprendió que era "una judía" fuera de su hogar? A pesar de pertenecer ella misma a una familia asimilada "a la pregunta ¿quién eres? Arendt responderá hasta el final de su vida: una judía" (Birulés, 2005, p. XII). Comprender esta afirmación requiere, entonces, algunas aclaraciones. Si bien la judeidad, como el hecho de ser mujer, es considerada por Arendt un "dato incontrovertible", algo que no ha sido elegido y en donde no ha intervenido su propia iniciativa, no se trata de reconocer un tipo particular de seres humanos sino de señalar un "presente político, una determinada configuración del mundo que nada tiene que ver con una determinada configuración natural o biológica” (Birulés, 2005, P. XIII).

Este es un aspecto muy importante en el pensamiento político de Arendt que es abordado de manera muy pertinente por algunas lectoras feministas (Birulés, Collin, Honig) que contribuye a esclarecer la forma en que Arendt entiende la acción y el juicio político. Cuando Arendt afirma que el primer mandato de la capacidad de juzgar es "pensar por sí misma", y cuando sostiene que la acción y el discurso corresponden a dar respuesta a la pregunta "¿quién eres?” y no simplemente “¿qué eres?” (1993, pp. 200-205), muchos intérpretes concluyen -erradamente- que se trata de un pensamiento desarraigado, deshistorizado y centrado en el individuo. Sin embargo, estas lecturas demuestran que Arendt no postula la posibilidad de actuar o pensar desidentificándose y desligándose de aquellos "datos incontrovertibles" de su vida, sino al contrario afirma la necesidad de "tomar posición, responder y a lo que nos ha sido dado" (Birulés, 2005, p. XVI). De forma que, la afirmación que Arendt sostiene en su entrevista con Günter Gauss "si te atacan como judío, debes defenderse como judío" (2010, p. 53), no es simple ni principalmente la afirmación de la identidad que se constituye por la alteridad, sino la asunción de que cualquier acción política, cualquier agencia, debe partir de aquella definición, de aquel dato contingente que es también y principalmente un dato político. Es decir que, para la autora, la única defensa que podía esgrimirse contra el antisemitismo debía hacerse desde el sostenimiento de la pertenencia al colectivo que está siendo atacado, al cual se intenta hacer desaparecer. 
En este sentido, los llamados escritos judios aportan una noción interesante para reconstruir su concepción política: el concepto de paria. En estos textos, Arendt analiza de qué manera la historia de la emancipación política y la asimilación social y cultural de los judíos en Europa significó una exigencia, por una parte, de desmembramiento del pueblo judío y, por la otra, de negación de la propia judeidad a fin de considerarse únicamente parte del género humano. Así, los judíos en Europa se subsumieron, dice Arendt, en dos grandes figuras: la del advenedizo (parvenus) y la del paria. Mientras el parvenu utilizaba su posición económica para obtener poder y convertirse así en judío de excepción -alejándose y negando a los estratos más pobres de la judería-, los judíos paria (conscientes o no) sufrían la segregación social y pagaban el costo que exigían las naciones europeas por su integración. Como señala Bernstein (1996), ambos compartieron la ambigua libertad de la emancipación y la ambigua igualdad de la asimilación y fueron parte de la paradójica historia de la constitución del Estado nación en Europa. Arendt advierte sobre las complejidades de estos procesos en "La tradición oculta" (2005), donde analiza los perfiles de cuatro biografías que le permiten profundizar en el concepto de paria,${ }^{6}$ es decir, las formas posibles de responder desde la propia identidad. Se trata, en este texto, de recuperar figuras importantes para escribir una historia de los judíos en Europa que la propia tradición judía descartaba por falta de pureza. Así, estos personajes constituyen para Arendt, ejemplos de una tradición oculta y un elemento central para considerar el lugar de los judíos en la terrible historia que luego protagonizaron.

En estas imágenes del pueblo judío como pueblo de parias y como pueblo paria, Arendt muestra tanto los pilares fundamentales sobre los que construye sus reflexiones sobre el pueblo como su crítica profunda al individualismo moderno sobre el cual se funda el Estado Nación. Asimismo, deja ver las críticas hacia una tradición judía que borra esta tradición oculta y por lo tanto, no logra ver la historia del pueblo judío que culminó con los totalitarismos. Critica la falta de politicidad del pueblo judío (el no haber actuado como comunidad política) y la falla de sus líderes, quienes prefirieron escalar en las jerarquías sociales a costa del pueblo judío que era subyugado y segregado. En efecto, en estos textos, como señala unos años más tarde en su libro sobre el totalitarismo, se muestran las

(p)rofundas, antiguas y fatales contradicciones (que) se ocultaban tras la abstracta y palpable inconsecuencia de que los judíos recibieran su ciudadanía de Gobiernos que, a lo largo de siglos, habían hecho de la nacionalidad un prerrequisito de la ciudadanía y de la homogeneidad de la población la característica más sobresaliente del cuerpo político. (Arendt, 1998, p. 35).

Lo que luego se expresará en la paradoja de los Derechos Humanos, aparece aquí como la conclusión del dilema que plantean los Estados Nación a los judíos a través de la demanda de asimilación, ser simplemente un ser humano. Ante ello, y ante las réplicas que pueden escucharse en las concepciones liberales del sujeto político, Arendt responde con contundencia: "Sólo dentro de un pueblo se puede ser humano y vivir como ser humano entre humanos" (2005, p. 74). Dicho de otra forma, para convertirse en un sujeto político, en un sujeto de derechos, es necesario formar parte de un colectivo; el proceso de subjetivación no puede ser nunca individual, sin una trama colectiva donde reconocerse y singularizarse.

El problema de la cuestión judía es que siempre se exigió una solución individual a un problema colectivo. Retomando las ideas de Lazare, Arendt sostiene que es a través de una acción en tanto que pueblo judío, que el mismo puede encontrar una salida política. Sin embargo, las condiciones para que dicha acción sea exitosa tienen que ver con las formas de organización del pueblo, con la reconstitución de su tradición y con sus acciones en relación con los otros pueblos. No es en tanto que pueblo homogéneo, nacional, étnico, caracterizado por su rol de victima o chivo expiatorio de la historia que el pueblo judío debe entrar en el espacio público. Es en la diversidad, en la plurinacionalidad, que los judíos pueden reconocer una tradición oculta, pero también en la conciencia de ser paria, que puede constituirse como pueblo sin subsumir la política a la etnicidad. ${ }^{7}$

Pueblo es, en su pensamiento político, al mismo tiempo 'lo dado' y el fruto de un organizarse a partir de interesse(s) comunes. 'Pertenecer a un grupo es antes que nada una condición natural ... Pero pertenecer a un grupo ..., en un segundo sentido, es decir, formando un grupo organizado, es cosa enteramente distinta" (Arendt, 2010, en Birulés, 2005, p. XVII).

\footnotetext{
Como señala Anabella Di Pego “Arendt realiza una reapropiación de las categorías de paria [pariah] y advenedizo [parvenu] del francés Bernard Lazare para analizar el estatuto social de los judíos. Ambas nociones serán retomadas también en su libro sobre el totalitarismo (1999, p. 107-120), caracterizándose el advenedizo por no tener escrúpulos en negar su identidad como judío para ser admitido en la sociedad en tanto que el paria se rebela contra estas exigencias y permanece en los márgenes de la sociedad" (2020,p. 11). Para Birulés, el paria consciente es quien toma la actitud de "sentir gratitud por el don recibido, por el presente de la judeidad o de cualquier otra diferencia y tomarlos como propios, tener iniciativa: re-presentarlos, ponerlos en juego, a través de la palabra y la acción, en un contexto donde se encuentran los otros y las otras” (2005, p. XV).

Seyla Benhabib indica que Arendt se esfuerza por distinguir ethnos y demos "Demos significa la nación como cuerpo de ciudadanos que se autogobierna y que puede ser o no étnicamente homogéneo, mientras que ethnos expresa la nación como una entidad que es étnica, lingüística y religiosamente homogénea" (Benhabib, 1996 citada en Birulés, 2005, XIX).
} 
Si ese sentimiento pudiera politizarse y tomarse como punto de partida para aliarse con otros pueblos paria -como proponía Lazare-, entonces el pueblo judío no se identificaría por oposición a quienes lo persiguen sino por oposición a los perseguidores de todos los pueblos. Lo que puede leerse en estos textos y en otros donde Arendt hace un llamamiento explícito a la autoorganización del pueblo judío, no es solo su fuerte crítica al Estado nación -que podrá escucharse de manera más articulada en otros de sus textos- sino una alternativa para la organización de los pueblos, como señala Richard Bernstein, desde abajo, participativamente, y en alianza con otros pueblos -ambos componentes centrales de su republicanismo-.

Pero, tanto la tendencia de identificar al pueblo judío con una supuesta "esencia" étnica como los desastrosos resultados de las masivas movilizaciones totalitarias, fueron trágicas lecciones para Arendt. Así, resulta importante para su pensamiento distinguir lo que constituye políticamente un pueblo de las apariciones y movilizaciones de otro tipo de colectivos. En efecto, para la autora, no todas las movilizaciones constituyen una entrada en acción del pueblo como tal. Como señalamos al principio de este apartado, según Canovan, Arendt distingue las manifestaciones políticas del pueblo de las movilizaciones anti-políticas de un no-pueblo. ${ }^{8}$

In Origins, in On Revolution, and elsewhere, she distinguishes between the People and various other collectivities. Indeed she comes up with at least four different non-Peoples: the Mob, the Masses, and the Tribe in Origins, and the starving multitude in On Revolution. All of these are mobilized for action, all are powerful, but none is the People [En Los origenes, en Sobre la revolución, y en otros lugares, ella distingue entre el Pueblo y varias otras formas de colectividades. De hecho, identifica al menos cuatro no-Pueblos diferentes: el populacho, las masas, la tribu en Los orígenes y la multitud en Sobre la revolución. Todos movilizados para la acción, todos poderosos, pero ninguno es el Pueblo]. (Canovan, 2002b, p. 404, nuestra traducción).

Frente a estas imágenes se levantan figuras de pueblo resistente y auto-organizado como le peuple, los sans-culottes como el verdadero cuerpo político, distinguible tanto de la población como de la sociedad. (Canovan, 2002b, p. 421).

El populacho, debido a su desarraigo, se presenta como presa fácil para la movilización de los movimientos, ya que estos resultaban una forma de mantener a los hombres unidos sin proveerles un mundo estable. Sin embargo, los movimientos totalitarios no significaron simplemente la movilización del populacho, sino la organización total de las masas. Canovan precisa la distinción: mientras que el populacho fue un fenómeno marginal, las masas incluyeron casi a todos en una sociedad que había sufrido convulsiones catastróficas a través de la guerra, la revolución, el colapso económico. Los miembros del populacho habían perdido su lugar en un mundo que todavía estaba en pie; las masas quedaron perdidas por el colapso del mundo en sí (2002, p. 407).

Es así que, según Canovan, lo que distingue al verdadero pueblo en el pensamiento de Arendt de estas manifestaciones de no-pueblo es su relación con el mundo y la realidad. Mientras que el pueblo comparte un mundo y un sentido común enraizado en la realidad, estas manifestaciones populares están alienadas tanto del mundo como de una realidad compartida. Su movilización política se basa en esta alienación y construye una realidad paralela a través de la ideología.

Más allá de las distinciones teóricas, Canovan reconoce que para Arendt, el pueblo no es un concepto ni una categoría que pueda ser definida sociológicamente, sino un fenómeno que ocurre o, mejor dicho, ha ocurrido en ciertos momentos de la historia. En este sentido, Arendt defiende la posibilidad de la aparición del pueblo aun en las sociedades de masas actuales y en contextos de grandes catástrofes como las que azotan el mundo contemporáneo. La historia de las revoluciones nos muestra que un pueblo puede aparecer y organizar su acción aun en condiciones de desestructuración social, de destrucción del tejido social y de desarraigo de las identidades sociales que lo sostienen. Es en este sentido que Arendt defiende en Sobre la revolución la idea de que:

No hay nada que se oponga tanto al antiguo adagio, según el cual la ausencia de coerción gubernamental determina la aparición inmediata de las inclinaciones "naturales" del pueblo hacia la anarquía, como la constitución de los consejos, los cuales en todas las circunstancias en que se presentaron, y de modo muy especial en la Revolución húngara, se preocuparon por la reorganización de la vida política y económica del país y del establecimiento de un orden nuevo. (Arendt, 1992, p. 281).

Es a través de la participación política que el pueblo aparece como tal y lo ha hecho, durante las revoluciones, menos como un estallido anárquico que para garantizar una forma de gobierno que protegiera su libertad política. La república arendtiana, por lo tanto, no puede concebirse sin la participación popular en este sentido que venimos precisando: en espacios de poder que aspiran a su institucionalización.

Non-people es un concepto de acuña Canovan y no pertenece al pensamiento de Arendt (Cf. Canovan, 2002b, p. 404). 


\section{A modo de conclusión: apuntes para pensar otro republicanismo}

Todo lo que hemos dicho hasta aquí nos permite un retrato del pensamiento político de Arendt como republicanopopulista o populista-republicano. De esta potente comunidad, en este trabajo destacamos dos ideas que, a nuestro entender, aportan algo más que inspiraciones para las disputas del presente.

Por una parte, Arendt nos muestra un pensamiento que es republicano-populista en la medida en que tiene en su centro una concepción particular de la libertad: la libertad implicada en la participación del demos en los asuntos comunes. Así, ante ciertas lecturas republicanas antipopulistas, cabe ofrecer la alternativa de otro republicanismo: uno que introduce un contrapunto en el debate sobre los sentidos de una libertad republicana y su ligazón con, antes que su oposición a, la denostada libertad democrática. Como sugerimos en el desarrollo de este breve texto, nos parece que aquella libertad como no-dominación que el neorrepublicanismo recuperó de la mano de Pettit, se centró demasiado en la idea de no-interferencia arbitraria, dejando de lado la centralidad que la misma había tenido en su versión maquiaveliana de la participación política como única garantía de la libertad. Así, la libertad republicana en el sentido arendtiano no puede escindirse de la acción política y, a su vez, dicha acción no puede identificarse simplemente en la capacidad de agencia del individuo -como muestra su lectura romana de la tradición griega.

Por otra parte, que su pensamiento es populista-republicano en la medida en que tiene en su centro una concepción particular de un pueblo activo que nutre su particular idea de libertad. Esta libertad no es estrictamente positiva en el sentido que asume desde la dicotómica definición de Berlin, ya que no subsume las singularidades a una voluntad unificada que oprima las capacidades de acción y elección de los hombres, sino que, a la inversa, para la autora, los hombres deben actuar en conjunto para establecer dicha libertad. Por ello, ante ciertas lecturas populistas anti republicanas, es posible habilitar la discusión sobre una veta republicana del populismo que, sin caer en versiones del pueblo unificado, tampoco nos arroje en su opuesto: la disolución del pueblo en un agregado de individuos. Su pensamiento nos permite, a la vez, pensar un republicanismo que no caiga en la dilución del individualismo liberal ni en una idea de participación popular que sea inmediatamente identificada con movimientos de masa antirrepublicanos.

Como intentamos mostrar, el pensamiento de Arendt exige distinguir entre diversas manifestaciones populares y, por lo tanto, nos permite un análisis más agudo de los fenómenos denominados populistas. En este sentido, nadie mejor que Arendt para comprender que no toda aparición colectiva representa una acción del pueblo, pero también nadie mejor que ella para señalar que toda acción política que aspire a la libertad debe ser una acción colectiva de un pueblo.

\section{Referencias bibliográficas}

Arendt, Hannah (1992). Sobre la revolución (Pedro Bravo, Trad.). Alianza.

Arendt, Hannah (1993). La condición humana (Ramón Gil Novales, Trad.). Paidós.

Arendt, Hannah (1996a). El concepto de Historia. En Entre pasado y futuro. Ocho ejercicios sobre la reflexión política (Ana Luisa Poljak Zorzut, Trad.; pp. 101-153). Península.

Arendt, Hannah (1996b). ¿Qué es la autoridad? En Entre pasado y futuro. Ocho ejercicios sobre la reflexión política (Ana Luisa Poljak Zorzut, Trad., pp. 101-153). Península.

Arendt, Hannah (1997). ¿Que es la Política? (Rosa Sala Carbó, Trad.). Paidós.

Arendt, Hannah (1998). Los orígenes del totalitarismo. Vol. 1, Antisemitismo. Alianza.

Arendt, Hannah (2005). La tradición oculta. En La tradición oculta (R.S. Carbó y Vicente Gómez Ibáñez, pp. 49-74). Paidós.

Arendt, Hannah (2010). Entrevista con Günter Gauss. En Lo que quiero es comprender. Sobre mi vida y mi obra (Manuel Abella y José Luis López de Lizaga, Trads., pp. 3-65). Trotta.

Benhabib, Seyla (2000). The reluctant modernism of Hannah Arendt [El reluctante modernismo de Hannah Arendt]. Rowman \& Littlefield.

Bernstein, Richard (1996). Hannah Arendt and the Jewish question [Hannah Arendt y la cuestión judía]. Massachusetts Institute of Technology.

Birulés, Fina (2005) Introducción: Hannah Arendt y la condición judía. En Hannah Arendt. Una revisión de la historia judia y otros ensayos (pp. IX-XXVII). Paidós.

Canovan, Margaret (2002a). Hannah Arendt: A reinterpretation of her political thought [Hannah Arendt: una reinterpretación de su pensamiento político]. Cambridge University.

Canovan, Margaret (2002b). The people, the masses and the mobilisation of power: the paradox of Hannah Arendt's "populism" [El pueblo, las masas y la movilización del poder: la paradoja del "populismo" de Hannah Arendt]. Social Research: An International Quarterly, 69(2), 403-422.

Canovan, Margaret (2005). The people [El pueblo]. Polity.

Carmona Hurtado, Jordi (2014). Paciencia de la acción, Hannah Arendt. Revista electrónica interlegere, 14, enero a junio. https://periodicos.ufrn.br/interlegere/article/view/4956/4309 
Di Pego, Anabella (2020). La cuestión judía y la falta de mundo en la modernidad desde la perspectiva de Hannah Arendt. Kriterion, 145, 7-30. doi: https://doi.org/10.1590/0100-512x2020n14501ap

Forti, Simona (2001). Vida del espíritu y tiempo de la polis (Irene Romero Pintor y Miguel Ángel Vena Cernuda). CátedraUniversidad de Valencia.

Funes, Ernesto (2004). La desunión: República y no-dominación en Maquiavelo. Gorla.

Habermas, Jürgen (2000). El concepto de poder en Hannah Arendt (Manuel Jiménez Redondo, Trad.). En Habermas, J. (Ed.), Perfiles filosóficos-políticos (pp. 205-222). Taurus.

Hunziker, Paula (2019). Notas arendtianas sobre La República de Rosler. Revista Discusiones, 23(Especial), 159-179. https://doi.org/10.52292/j.dsc.2019.2219

Leibovici, Martine (2005). Hannah Arendt y la tradición judia. El judaísmo a prueba de la secularización (Esther Cohen y Silvana Rabinovich, Trads.). Universidad Nacional Autónoma de México.

Maquiavelo, Nicolás (1996). Discursos sobre la primera década de Tito Livio (Ana Martínez Arancón, Trad.). Alianza.

Pettit, Philip (1999). Republicanismo. Una teoría sobre la libertad y el gobierno (Toni Domènech, Trad.). Paidós.

Pocock, J. G. A (2002). El momento maquiavélico. El pensamiento político florentino y la tradición republicana atlántica (Marta Vázquez-Pimentel y Eloy García, Trad.). Tecnos.

Quintana, Laura (2015). ¿Instituir o constituir la libertad? La doble apuesta de Sobre la revolución. En Marco Estrada Saavedra, María Teresa Muñoz, (Comps.), Revolución y violencia en la filosofia de Hannah Arendt : reflexiones críticas (pp. ). El Colegio de México, Centro de Estudios Sociológicos.

Rosler, Andrés (2016). Razones públicas. Seis conceptos básicos sobre la república. Katz.

Taminiaux, Jacques (1998). Arendt y Heidegger. Areté. Revista de Filosofia, 10(1), 135-147.

Tassin, Etienne (2012). Le malefice de la vie à plusieurs. La politique est-elle vouée à l'échec. [El maleficio de la vida en común ¿la política está condenada al fracaso?] Bayard. 